\title{
The effect of contactor area on vibrotactile magnitude function exponents for the tongue and hand
}

\author{
DONALD FUCCI, DANIEL HARRIS, and LINDA PETROSINO \\ Ohio University, Athens, Ohio
}

\begin{abstract}
The method of magnitude production was used to investigate subjective vibratory magnitude functions for the hand and tongue. Three different contactor areas were employed. The subjects were 10 normal young adults. The results indicated that magnitude slope functions were inversely related to contactor area for both structures tested. The results suggest that the number of sensory units activated by a stimulus may be an important variable in establishing vibratory sensation magnitude functions.
\end{abstract}

Literature on neurophysiological mechanisms of cutaneous mechanoreception includes research concerned with suprathreshold levels of stimulation. This research was performed initially to gain a better understanding of audition (Békésy, 1960) and to aid in the development of cutaneous communication systems (Geldard, 1961). Stevens (1961) performed a series of investigations relating subjective responses to stimulus intensities. Using the methods of magnitude estimation and production, he demonstrated that a power law function successfully describes the relationship between subjective intensity and the amplitude of vibration at the fingertip (Stevens, 1957). More recently, several researchers have begun to systematically study the various parameters that can have an effect on suprathreshold vibrotactile power functions. Parameters such as psychophysical scaling method, body site stimulated, the use of a rigid surface to surround the contactor, frequency at which scaling is performed, and signal duration have been found to have an effect on the magnitude functions obtained (Verrillo \& Capraro, 1975; Verrillo \& Chamberlain, 1972; Verrillo, Fraioli, \& Smith, 1969; Verrillo \& Smith, 1976; Zwislocki \& Goodman, 1980).

The surface area of the contactors used in magnitude scaling is another parameter that has received some investigation. Verrillo and Chamberlain (1972) compared magnitude functions produced with contactor areas of .28 and $2.9 \mathrm{~cm}^{2}$ on the thenar eminence of the right hand. The results showed that an increase in contactor area was accompanied by a decrease in slope value. The authors suggested that subjective magnitude slope functions are influenced by the number of sensory units activated by a stimulus.

The authors' mailing address is: School of Hearing and Speech Sciences, Ohio University, Athens, Ohio 45701.
The purpose of the present study was to further investigate the effects of contactor area on subjective vibrotactile magnitude functions. To date, no information on the effects of the smaller contactor area consistently used in lingual vibrotactile research has been collected.

\section{METHOD}

The vibrotactile instrumentation consisted of a stimulus unit and a measurement unit. The stimulus unit was composed of a sine wave generator, an experimenter-controlled variable attenuator, a subject-controlled variable attenuator, two universal timers, an audio amplifier, a power amplifier, a preamplifier, and an electromagnetic minivibrator with a contactor extension. The pulsed vibratory signal generated had a $50 \%$ duty cycle (on $500 \mathrm{msec}$ and off $500 \mathrm{msec}$ ), with a rise and decay time of $100 \mathrm{msec}$. The measurement unit included an accelerometer, a cathode follower, a microphone amplifier, and a voltmeter. A detailed description of the vibrotactile equipment and procedures can be found in a review by Fucci, Petrosino, Wallace, and Small (1982).

Ten subjects ranging in age from 18 to 21 years (mean $=19.4$ years) were employed in this study. All subjects were treated in the same manner. Each subject was seated in an adjustable chair and asked to place the appropriate structure to be tested against the bottom of a rigidly mounted plastic disk. The anterior midline section of the dorsum of the tongue and the thenar eminence of the right hand were the two test sites employed. Three different contactor areas $\left(.128, .32\right.$, and $\left.1.3 \mathrm{~cm}^{2}\right)$ were used for both test sites for all 10 subjects. Each of the three contactors had a corresponding plastic disk that was designed to include a hole allowing a 1-mm gap between the contactor and the disk.

The psychophysical method of magnitude production was used to establish suprathreshold magnitude functions. This method was selected because it had been shown to be very stable (Zwislocki \& Goodman, 1980). The procedure used did not incorporate a standard modulus (Zwislocki \& Goodman, 1980). The magnitude production task was performed at a signal frequency of $250 \mathrm{~Hz}$. The contactors were randomized across subjects. Each subject was presented with a series of six numbers $(5,10,15,20,25$, and 30) that were presented randomly, and was asked to adjust the magnitude of the stimulus he or she was feeling to the number being presented. The subject-controlled attenuator consisted of a smooth unmarked knob (120-dB variable potentiometer) having no visual or 
mechanical cues. The experimenter was in control of a master attenuator that could be used to vary the actual stimulus amplitude with respect to the position of the subject's attenuator knob (Zwislocki \& Goodman, 1980).

Three runs of the randomized series of six numbers were presented to all 10 subjects for both test sites and each contactor. The first run of each subject was discarded, and the geometric means of the second and third runs were accepted as the produced amplitudes (Verrillo et al., 1969). The results of the magnitude production task for all subjects were recorded in millivolts and converted to displacement in decibels re $1 \mu$ peak. Group data were generated by deriving geometric means of the magnitude production amplitudes across all subjects for both test sites and each contactor.

\section{RESULTS AND DISCUSSION}

Figure 1 shows the 10 subjects' results for the magnitude production task performed for the lingual dorsum. Figure 2 shows the 10 subjects' results for the magnitude production task performed for the thenar eminence. The data show that the mechanoreceptive mechanisms located within the anterior dorsal portion of the tongue and the thenar eminence can be used to produce suprathreshold magnitude functions that are compatible with those described in the literature. The curve slopes are very similar to each other and to those reported in other investigations in which a standard reference was not employed (Fucci \& Petrosino, 1982; Fucci \& Petrosino, 1983; Verrillo \& Capraro, 1975; Verrillo \& Chamberlain, 1972; Verrillo, Fraioli, \& Smith, 1969; Zwislocki \& Goodman, 1980). The upper portions of the curves are compatible with Stevens's (1961) power function law, and the entire curves are compatible with Zwislocki's (1965) and Atkinson's (1982) modifications of Stevens's law, which account for the

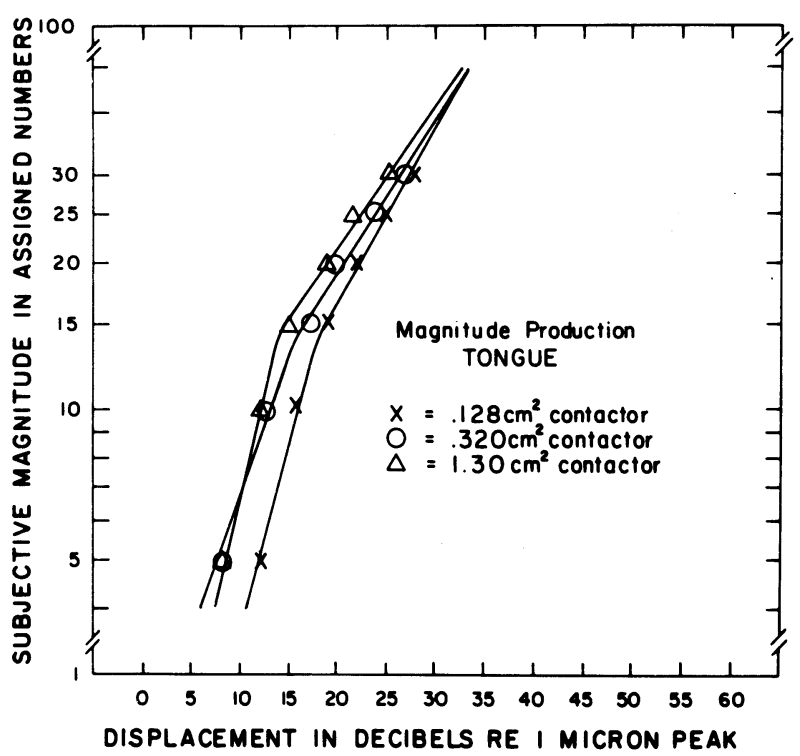

Figure 1. Subjective vibrotactile magnitude slopes for the lingual dorsum produced using three different contactor areas.

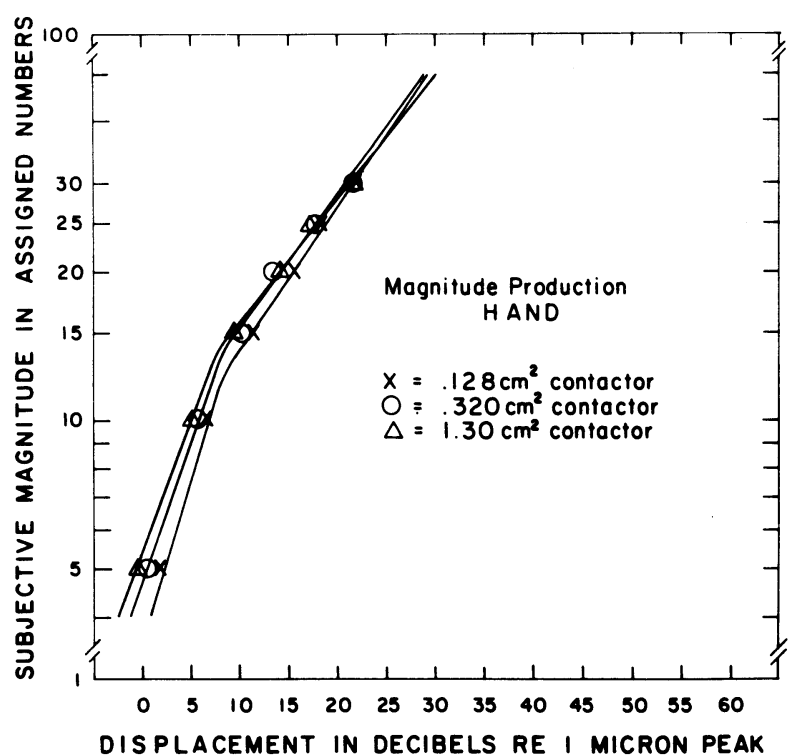

Figure 2. Subjective vibrotactile magnitude slopes for the thenar eminence produced using three different contactor areas.

steeper sloping of the curves at values closer to threshold. The slope values for the anterior lingual dorsum when contactors with areas of $.128, .32$, and $1.3 \mathrm{~cm}^{2}$ were used were $0.72,0.61$, and 0.59 , respectively. The slope values for the thenar eminence with the same contactors were $0.59,0.54$, and 0.50 , respectively. The slopes are reported in terms of power. The results of this study indicated that the subjects produced decreasing magnitude functions (shallower slopes) for both the tongue and the hand with contactors of increasing areas.

The current study produced results in agreement with those of an investigation by Verrillo and Chamberlain (1972). In their study, the methods of magnitude estimation and magnitude production were used to calculate magnitude balance functions for the distal pad of the middle finger, the thenar eminence, and the volar forearm. The two contactors used had areas of .28 and $2.9 \mathrm{~cm}^{2}$. The test frequency was $250 \mathrm{~Hz}$. The results demonstrated that the use of the larger contactor produced lower magnitude functions than did the use of the smaller contactor when a rigid surround was employed. Verrillo and Chamberlain suggested that slope values were inversely related to the number of sensory units activated.

In the current study, the decrease in slope values observed for both the tongue and the hand when contactor area was increased appears to follow the pattern described by Verrillo and Chamberlain (1972). The size and shape of the tongue determined the upper limit of the contactor areas that could be used in the current investigation. Consequently, an exact matching of the larger contactor with that used by 
Verrillo and Chamberlain was impossible. The agreement of results between the two studies, even though the larger contactors were not of the same size, suggests that the number of sensory units activated by a stimulus is an important variable in establishing vibratory sensation magnitude functions (Verrillo and Chamberlain, 1972). This appears to be the case for the tongue as well as for the hand.

\section{REFERENCES}

Atkinson, W. H. A general equation for sensory magnitude. Perception \& Psychophysics, 1982, 31, 26-40.

BÉ KÉSY, G. voN Experiments in hearing. New York: McGrawHill, 1960.

Fucci, D., \& Petrosino, L. Lingual vibrotactile sensation magnitudes: Stimulus frequency effect. Bulletin of the Psychonomic Society, 1982, 20, 224-226.

Fucci, D., \& Petrosino, L. Lingual vibrotactile sensation magnitudes: Comparisons of suprathreshold responses in men and women. Perception \& Psychophysics, 1983, 33, 93-95.

Fucci, D., Petrosino, L., Wallace, D., \& Small, L. Modification of instrumentation for research on lingual vibrotactile sensitivity: Elimination of the tongue clamping procedure. Review of Scientific Instruments, 1982, 53, 1294-1296.

Geldard, F. A. Cutaneous channels of communication. In
W. A. Rosenblith (Ed.), Sensory communication. New York: Wiley, 1961.

Stevens, S. S. On the psychophysical law. Psychological Review, 1957, 64, 153-181.

STEvens, S. S. The psychophysics of sensory function. In W. A. Rosenblith (Ed.), Sensory communication. New York: Wiley, 1961.

Verrillo, R. T., \& Capraro, A. Effects of stimulus frequency on subjective vibrotactile magnitude functions. Perception \& Psychophysics, 1975, 17, 91-96.

Verrillo, R. T., \& Chamberlain, S. C. The effect of neural density and contactor surround on vibrotactile sensation magnitude. Perception \& Psychophysics, 1972, 11, 117-120.

Verrillo, R. T., Fraioli, A. J., \& Smith, R. L. Sensation magnitude of vibrotactile stimuli. Perception \& Psychophysics, 1969, 6, 366-372.

Verrillo, R. T., \& SMith, R. Effects of stimulus duration on vibrotactile sensation magnitude. Bulletin of the Psychonomic Society, 1976, 8, 112-114.

Zwislock I, J. Analysis of some auditory characteristics. In R. D. Luce, R. B. Bush, \& E. Galanter (Eds.), Handbook of mathematical psychology (Vol. 3). New York: Wiley, 1965.

Zwislocki, J., \& Goodman, D. Absolute scaling of sensory magnitudes: A validation. Perception \& Psychophysics, 1980, 28, 28-38.

(Manuscript received for publication July 20, 1983.) 